\title{
Role of media reports in completed and prevented suicide: Werther $v$. Papageno effects
}

Thomas Niederkrotenthaler, Martin Voracek, Arno Herberth, Benedikt Till, Markus Strauss, Elmar Etzersdorfer, Brigitte Eisenwort and Gernot Sonneck

\section{Background}

Media reporting of suicide has repeatedly been shown to trigger suicidal behaviour. Few studies have investigated the associations between specific media content and suicide rates. Even less is known about the possible preventive effects of suicide-related media content.

\begin{abstract}
Aims
To test the hypotheses that certain media content is associated with an increase in suicide, suggesting a so-called Werther effect, and that other content is associated with a decrease in suicide, conceptualised as a Papageno effect. Further, to identify classes of media articles with similar reporting profiles and to test for associations between these classes and suicide.
\end{abstract}

\section{Method}

Content analysis and latent class analysis (LCA) of 497 suicide-related print media reports published in Austria between 1 January and 30 June 2005. Ecological study to identify associations between media item content and shortterm changes in suicide rates.

\section{Results}

Repetitive reporting of the same suicide and the reporting of suicide myths were positively associated with suicide rates. Coverage of individual suicidal ideation not accompanied by suicidal behaviour was negatively associated with suicide rates. The LCA yielded four classes of media reports, of which the mastery of crisis class (articles on individuals who adopted coping strategies other than suicidal behaviour in adverse circumstances) was negatively associated with suicide, whereas the expert opinion class and the epidemiological facts class were positively associated with suicide.

\section{Conclusions}

The impact of suicide reporting may not be restricted to harmful effects; rather, coverage of positive coping in adverse circumstances, as covered in media items about suicidal ideation, may have protective effects.

\section{Declaration of interest}

None.
Evidence suggests that there is an increase in suicides following media reports of suicide, which is frequently referred to as copycat behaviour or as the Werther effect, ${ }^{1}$ although the effect size is smaller than for other psychosocial risk factors for suicide. ${ }^{2}$ The risk is thought to depend not only on reader characteristics, ${ }^{2,3}$ but also on media content. ${ }^{3-5}$ In order to promote safe media content, the World Health Organization (WHO) and national agencies have developed guidelines for the reporting of suicides. ${ }^{5,6}$ The guidelines list reporting characteristics that may either prevent or trigger suicides, thus serving as educational material for journalists and editors. But most of the recommendations put forth in these guidelines have not yet been empirically tested. ${ }^{7}$ In particular, there is a lack of knowledge about protective reporting characteristics, although the suicide-protective potential of reporting of positive coping in adverse circumstances has been discussed on a theoretical basis. ${ }^{6}$ Specifically, it has been found that media items referring to suicidal ideation are associated with a lower risk of a post-report increase in suicide than other media items. $^{4}$

In the present study, we performed a content analysis of suicide-related media reports. To identify potentially protective and harmful reporting characteristics we tested associations between specific components of media reports, and also classes of reports with similar reporting profiles, and short-term changes in suicide rates. We hypothesised that changes in suicide rates following the publication of media items would vary with the circulation rates of the media items in the population. Based on Papageno's overcoming of a suicidal crisis in Mozart's opera The Magic Flute, we conceptualised any suicide-protective impact of media reporting as a Papageno effect. In Mozart's opera, Papageno becomes suicidal upon fearing the loss of his beloved Papagena; however, he refrains from suicide because of three boys who draw his attention to alternative coping strategies. ${ }^{8,9}$

\section{Method}

\section{Sample of media reports}

We obtained all reports from the 11 largest Austrian nationwide newspapers that included the term suicide between 1 January and 30 June 2005 from the Austrian Press Agency. Each of these newspapers has coverage rates exceeding $1 \%$ of the population. Articles using 'self-murder' (original search term: selbstmord) or 'free death' (freitod) were also included, because of their frequent use as German synonyms for suicide. The search yielded 1055 articles. We excluded items that used suicide only as a metaphor $(n=92)$, were about suicide bombing $(n=381)$, mentioned suicide briefly $(<50 \%$ of the article) but were on topics not related to suicide $(n=113)$ or were located in the movie or television listings or in the classified advertisements $(n=58)$. The final sample comprised 497 items.

\section{Content analysis of media items}

\section{Basic item characteristics}

Several media reporting characteristics have previously been shown to be associated with an increase in suicides. These characteristics are: quantity of reporting; ${ }^{1,4}$ main focus of the item; ${ }^{4}$ reported suicide method; ${ }^{10-12}$ prominence of the item; ${ }^{13}$ and fictionality of the item. ${ }^{14}$ These codes were conceptualised as a code family 'basic item characteristics'. Each of the codes comprised several subcodes that were defined in accordance with 
the literature (see below). Coding examples are shown to exemplify the subcodes 'suicidal ideation' and 'suicide attempt'.

(a) Quantity of reporting:

(i) repetitive reporting: count of reports on the same event in the sample;

(ii) density of reporting: count of suicide-related articles on the day of publication.

(b) Main focus:

(i) completed suicide: item is on a case of completed suicide;

(ii) attempted suicide: item is on a case of attempted suicide. Also, a suicidal act stopped by another person immediately before the act qualifies as an attempted suicide; ${ }^{15}$

(iii) homicide suicide: item is on a homicide (attempt); murderer is suicidal;

(iv) suicidal ideation: item is on a case of suicidal ideation not accompanied by suicide attempt or suicide. Also, an aborted suicide attempt qualifies as suicidal ideation, in that it refers to an act in which an individual is one step away from attempting suicide, but changes her or his mind immediately before. ${ }^{15}$

Coding examples (in parentheses: location of the text segment in the sample):

'Before [Tom Jones] had his first hit, he thought about suicide . . . and wanted to jump in front of an Underground train in London ... In 1965, before he made the charts with "It's not unusual", he thought for second: "If I just take a step to the right, then it'll all be over".' (s-495)

'J.L. suffered from severe chronic pain for 37 years and was addicted to painkillers ... up until 1978. "At that time ... I considered the things I could do, one of them was suicide", says the entertainer.' (s-327).

(v) prevention programme: item is primarily on an initiative to prevent suicide, not on a case of suicidal behaviour;

(vi) suicide research: item is primarily on suicide-related research, epidemiology, statistics, not on a case of suicidal behaviour.

(c) Reported method:
(i) hanging;
(ii) jumping: jumping in front of moving objects/from great heights;
(iii) shooting;
(iv) drowning;
(v) poisoning;
(vi) other method.

(d) Prominence:

(i) front page: item is located on the front page;

(e) Fictionality:

(i) content is fictional.

\section{Qualitative item characteristics}

The main content analysis aimed at identifying consistencies and inconsistencies between media reports and media recommendations for suicide reporting. We obtained 15 international guidelines for reporting on suicide from the WHO and from national agencies, with guidelines stemming from the USA, Europe, Australia and Asia (see online supplement). These media recommendations have previously been compared and judged to be similar. ${ }^{7}$

Three coders (T.N., B.T., A.H.) were involved in the development of an outline for preliminary categorisation. There was a broad consensus among the coders about the thematic areas covered in the guidelines. Each of the recommendations listed as harmful focused either on the portrayal of the identity of the suicidal person; the suicidal act; the causes of suicidality; the effects of suicidality; or on the style and wording of the article. The recommendations listed as protective all focused on the reporting of background information on suicidality. We conceptualised each of these topics as a code prior to exploration of the media reports and attached subcodes based on each recommendation in the guidelines to that code. Only recommendations listed in more than one of the media guidelines were conceptualised as distinctive subcodes. Subcodes listed as harmful were conceptualised as a code family of 'harmful item characteristics' and distinguished from codes listed as protective (code family: 'protective item characteristics').

In an iterative process of coding 100 articles for training purposes, the media reports were explored and theoretical codes were brought together with the text. In some cases, the subcodes turned out not to be relevant to the text on its own, and closely connected themes were merged. The values used for all codes, except for article length and sensationalism (see below), were the presence of a code (1) and its absence (0). The unit of text analysis was always the complete article. The coders developed a code book with definitions of the subcodes, along with coding examples. The following list of distinctive codes and subcodes was used. For tabulated code definitions and coding examples see online Table DS1.

\section{Harmful item characteristics}

(a) Identity of the suicidal person:

(i) name reported;

(ii) description of character.

(b) Suicidal act:

(i) method in headline;

(ii) step-by-step 'guide' (i.e. how to use a suicide method);

(iii) suicide location reported;

(iv) suicide pact or mass suicide reported.

(c) Causes of suicidality:

(i) life event(s) related to suicide reported;

(ii) societal problems reported as having increased;

(iii) monocausality;

(iv) citation from suicide note.

(d) Effects of suicidality:

(i) effects on bereaved;

(ii) effects of suicidal act on public life;

(iii) immediate death without suffering reported.

(e) Style and wording:

(i) photograph;

(ii) several independent suicidal acts reported;

(iii) reference to a suicide epidemic;

(iv) headline explicitly on suicide;

(v) public myths reported;

(vi) article length;

(vii) sensationalism (see below).

\section{Protective item characteristics}

(a) Background information:
(i) focus on suicidal ideation;
(ii) focus on prevention programme;
(iii) focus on suicide research;
(iv) expert opinion reported;
(v) mental disorder related to suicide;
(vi) myths debunked;
(vii) contact information for support service; address or telephone number of a support service reported;
(viii) suicide-related statistical data reported;
(ix) suffering of suicidal person resulting from suicidal act reported.

\section{A linguistic approach to measuring sensationalism}

The recommendations in media guidelines to avoid sensationalism required a more indirect method of operationalisation than was 
the case for the other qualitative variables. Sensationalism is a prominent feature of the tabloid media. ${ }^{16}$ More generally, the tabloid media are characterised by large amounts of emotionality ${ }^{16}$ reduction in complexity (as indicated by short sentences), ${ }^{17}$ large amounts of dichotomous thinking ${ }^{18}$ and a lack of richness of vocabulary. ${ }^{19}$ Dichotomous thinking and restricted use of language have also been found in suicidal individuals, ${ }^{20}$ and are often jointly referred to as 'suicidal constriction'. Suicidal individuals may be confirmed in their constriction by media items that mimic their own constrictive thinking. The following four subcodes of sensationalism were developed to measure sentence length, emotionality, dichotomous thinking, and richness of vocabulary.

(a) Sentence length: the word count divided by the number of sentences.

(b) Emotionality: the Affective Dictionary Ulm contains 183 words extracted from German newspapers that were evaluated as indicating high emotionality ${ }^{21}$ (e.g. aggression, murder, pressure, jealousy, hatred, explosion, crisis, pain, scream). The nouns and corresponding adjectives and verbs were included as indicator words; any inflected forms were also considered. To obtain an 'emotionality score', we calculated the proportion of these indicator words in the total word count.

(c) Dichotomous thinking: this is characterised by a high amount of certainty. ${ }^{20}$ We obtained lists of the most frequent words expressing high certainty $(n=53$; e.g. certain, proven, undeniable) and low certainty ( $n=57$; e.g. doubtful, maybe, potentially, nearly) from the linguistic literature ${ }^{20}$ and calculated for each item a certainty score, defined as the number of words indicating high certainty divided by the count of all words related to certainty.

(d) Standardised type/token ratio: richness of vocabulary was defined as the average proportion of new words in consecutive text fragments of 100 words, which is referred to as the standardised type/token ratio. ${ }^{19}$

We programmed a MySQL database (MySQL 5.1, München, Sun Microsystems; www.mysql.de) for Windows XP to calculate the linguistic parameters semi-automatically.

\section{Rating agreement}

Intercoder reliability was measured for all qualitative codes. In total, a sample of 100 items that were not a subset of the full sample of units to be coded served for informal training and pilot testing. Codes not reaching the threshold value of $90 \%$ agreement during informal training were discussed among the coders and refined. Upon reaching a satisfactory agreement level (90\%) for all codes, we repeated this procedure as a pilot test, using a sample of 30 training text units that were different from the ones used in the informal test. The time needed for the training process was about $40 \mathrm{~h}$.

We evaluated intercoder reliability after completion of the text analysis, using 40 randomly selected text items from the main sample. Two coders (A.H. and B.T.) coded these items independently of the main coder (T.N.). We used two different indices, namely the simple percentage of agreement and Krippendorff's $\alpha,{ }^{22}$ to measure the level of agreement between coders. Krippendorff's $\alpha$ coefficient, which seemed most appropriate because of its applicability to nominal data, ${ }^{22}$ ranged from 0.80 to 1 , implying a high level of agreement. These values correspond to agreement percentages exceeding $90 \%$.

\section{Quantitative analysis}

The quantitative analysis aimed at measuring associations between item contents and suicide rates. Statistics Austria (www.statistik.at/) provided daily data on suicides for each Austrian federal state for the time period December 2004 to July 2005 as well as data on the population sizes. The outcome variable (suicide) was defined as the difference between the suicide rates (suicides per 100000 total population) in the week preceding the publication date and in the week after publication. More specifically, days -14 to -8 (where day 0 marks the publication date) were defined as the prepublication period and days 0 to 6 were the corresponding postpublication period. We did not use the week immediately preceding the publication date as the pre-period because of the possibility that other media (e.g. television or internet) may have reported the suicidal event slightly earlier than the newspapers. This, given the corresponding impact of these media, might have led to contamination of the data. Only suicides that occurred in the key market of the respective media item, i.e. the area where more than $10 \%$ of the population were exposed to the item, were used for the calculation of the outcome variable. In total, there were 18 key markets. Nine out of the 11 newspapers analysed had just one key market each; the 2 remaining newspapers each had several overlapping key markets. These newspapers produced regionally differing editions of their papers. The population sizes of the key markets ranged from 362000 to 3492000 , with each market comprising one or more of the nine Austrian federal states. The sociodemographic profile of the population was similar across the key markets with regard to age and gender. ${ }^{23}$ The proportion of people living in urban areas ranged from 51 to $100 \%$ for the different key markets. ${ }^{23}$

We assigned each media item to its key market, and the change in the suicide rate was assigned to the item. Seven items $(1.4 \%)$ were not published in an area with item coverage of over $10 \%$. These items were excluded. For an overview of the suicide rates and article counts in the ten most frequent key markets (altogether containing 477 items (97.3\% of all items)), see Fig. 1. Data on the circulation rates of newspapers across the country were obtained from Media Analysis Austria (2005). ${ }^{24}$ Data on the local editions including individual items were obtained from the Austrian Press Agency.

Point-biserial and Pearson correlation coefficients were calculated to quantify the associations between the qualitative characteristics of the items and suicide rates. The codes in the family 'basic item characteristics' were tested alongside significant qualitative variables in a multivariate model. This model included controls for the newspaper in which the item was published, because local factors relevant to the specific key markets of newspapers (e.g. degree of urbanisation) may have an impact on media effects. In addition, we controlled for month of publication, thus accounting for seasonal variation in suicide rates, which might also influence media effects. ${ }^{2}$

To assess whether post-item changes in suicide rates varied with the circulation rates of the media items we compared the absolute value of the change in the suicide rate in key markets with the change in the rate in those parts of the country where coverage rates were under $10 \%$ using an independent groups $t$-test for unequal variances (Welch's test). Data analysis was performed in SPSS 15 for Windows XP.

\section{Latent class analysis}

Potentially protective and harmful item characteristics may form classes based on the reporting strategy applied in the production of the report. Latent class analysis (LCA), a method with manifold applications in psychiatry and related fields, ${ }^{25-27}$ postulates that 


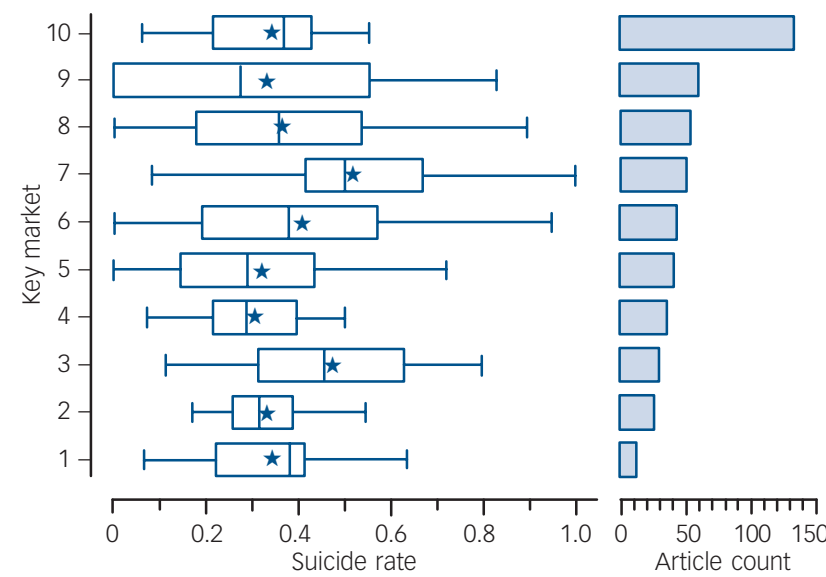

Fig. 1 Key markets: suicides rates and article counts

Box plots of weekly suicide rates (deaths/100 000 population and article counts for each of the ten most frequent key markets of the Austrian newspapers in the observation period (January to June 2005). Boxes represent values between 25th and 75th percentiles; whiskers, the upper and lower adjacent values; vertical lines, the median; $\star$, the arithmetic mean. associations among a set of observed variables are the result of a common underlying latent class structure. The goal of LCA is to identify the smallest number of latent classes that adequately describes the associations between observed variables, starting with a one-class model and proceeding to successive models with increasing class numbers. ${ }^{25,27}$ Information about the class structure is given by the latent class probabilities, which indicate the proportion of the sample assigned to each class, and by response probabilities, which are the proportions of class members reporting each item characteristic. ${ }^{25,26}$ In addition to the indicator variables that define classes, covariates, which control and describe the classes, can be included in the model. We used all the item characteristics listed as potentially protective, and also the harmful characteristics that were significantly associated with suicide rates, as indicators in the bivariate analyses. As a result of their practical relevance in describing suicide reports, we controlled for several basic item characteristics, namely for the quantity of reporting (variable: 'repetitive reporting'), for the focus on a completed suicide, and for article length. Consistent with the literature, ${ }^{27}$ we utilised two LCA modules in the Latent Gold 4.5 software for Windows XP, namely latent class cluster analysis and latent class factor analysis, to identify the best fitting solution.

The latent class cluster algorithm differs from traditional cluster algorithms, which group cases near each other according to some definition of distance. It defines one cluster per latent class, using model-based probabilities to classify cases. ${ }^{26}$ Latent class factor analysis treats the latent classes as factors, but avoids problems inherent in traditional factor analysis, such as having to rotate factors and having to assume continuous observed variables. $^{26}$

The fit statistics served as a tool for model selection. The observed frequencies of item characteristics were compared with the expected frequencies predicted by the model by calculating a likelihood-ratio goodness of fit value. ${ }^{25,26}$ Because there were sparse contingency tables, the likelihood-ratio statistic did not follow a chi-squared distribution; hence, we calculated bootstrapped $P$-values. Models were compared using the Bayesian information criterion and via the percentages of classification error. ${ }^{25,26}$ Further, we analysed bivariate residuals between pairs of observed variables. The initial assumption of local independence of pairs of variables with high residuals $(>3.84)$ was relaxed to improve model fit. ${ }^{25,26}$ Finally, we allowed for correlations among identified factors. This strategy is recommended whenever theoretical expectation suggests that the dimensions of an underlying structure are not completely mutually independent. ${ }^{28}$ Based on the most probable class assignment of media items, we calculated the correlation coefficients of classes with post-report changes in suicide rates.

\section{Results}

The frequencies of basic item characteristics and of potentially harmful and potentially protective characteristics are displayed in Tables 1-3.

\section{Bivariate analysis}

\section{Basic item characteristics}

There was a positive association between repetitive reporting and suicide rates. Reports on suicides by jumping and a main item focus on suicide research were positively associated with suicide rates, whereas a main focus on suicidal ideation was negatively associated with suicide rates (Table 1).

\section{Harmful item characteristics}

Media items explicitly stating that societal problems related to suicide are increasing, items reporting several independent suicidal acts, language referring to a suicide epidemic, reporting of public myths and the amount of dichotomous thinking were all positively associated with suicide rates (Table 2 ).

\section{Protective item characteristics}

Apart from a main item focus on suicidal ideation, none of the potentially protective item characteristics was associated with a

\begin{tabular}{|c|c|c|c|c|}
\hline Codes and subcodes & $n$ & $\%$ & $r^{a}$ & $P$ \\
\hline \multicolumn{5}{|l|}{ Quantity of reporting } \\
\hline Repetitive reporting ${ }^{\mathrm{b}}$ & - & - & 0.12 & 0.01 \\
\hline Density of reporting ${ }^{b}$ & - & - & 0.03 & 0.46 \\
\hline \multicolumn{5}{|l|}{ Main focus } \\
\hline Completed suicide & 234 & 47.0 & 0.001 & 0.98 \\
\hline Attempted suicide & 44 & 8.9 & 0.02 & 0.68 \\
\hline Homicide suicide & 95 & 19.1 & -0.02 & 0.66 \\
\hline Suicidal ideation & 26 & 5.2 & -0.15 & 0.001 \\
\hline Prevention programme & 31 & 6.2 & 0.09 & 0.06 \\
\hline Suicide research & 26 & 5.2 & 0.12 & 0.01 \\
\hline \multicolumn{5}{|l|}{ Reported method } \\
\hline Hanging & 52 & 10.4 & -0.08 & 0.07 \\
\hline Jumping & 59 & 11.8 & 0.15 & 0.001 \\
\hline Shooting & 79 & 15.9 & -0.05 & 0.28 \\
\hline Drowning & 20 & 4.0 & 0.005 & 0.91 \\
\hline Poisoning & 41 & 8.2 & 0.05 & 0.24 \\
\hline Other method & 41 & 8.2 & 0.005 & 0.91 \\
\hline \multicolumn{5}{|l|}{ Prominence } \\
\hline Front page & 16 & 3.2 & 0.05 & 0.28 \\
\hline Fictionality: content fictional & 22 & 4.4 & -0.03 & 0.56 \\
\hline \multicolumn{5}{|c|}{$\begin{array}{l}\text { a. Point-biserial correlation was used for dichotomous variables; Pearson correlation } \\
\text { for continuous variables. All tests two-tailed. } \\
\text { b. Continuous variable. All others: categorical variables, dummy-coded: presence (1) } \\
\text { versus absence (0) of the item characteristic. }\end{array}$} \\
\hline
\end{tabular}




\begin{tabular}{|c|c|c|c|c|}
\hline Codes and subcodes & $n$ & $\%$ & $r^{\mathrm{a}}$ & $P$ \\
\hline \multicolumn{5}{|l|}{ Identity of the suicidal person } \\
\hline Name reported & 117 & 23.5 & -0.02 & 0.59 \\
\hline Description of character & 31 & 6.2 & -0.07 & 0.11 \\
\hline \multicolumn{5}{|l|}{ Suicidal act } \\
\hline Method in headline & 69 & 13.9 & 0.05 & 0.25 \\
\hline Step-by-step 'guide' & 107 & 21.5 & 0.05 & 0.30 \\
\hline Suicide location reported & 66 & 13.3 & 0.03 & 0.45 \\
\hline $\begin{array}{l}\text { Mass suicide or suicide pact } \\
\text { reported }\end{array}$ & 11 & 3.8 & 0.01 & 0.90 \\
\hline \multicolumn{5}{|l|}{ Causes of suicidality } \\
\hline Life event(s) reported & 228 & 45.8 & 0.01 & 0.77 \\
\hline Monocausality & 148 & 29.7 & -0.07 & 0.15 \\
\hline Societal problems reported & & & & \\
\hline to have increased & 23 & 4.6 & 0.09 & 0.05 \\
\hline Citation from suicide note & 24 & 4.8 & -0.05 & 0.29 \\
\hline \multicolumn{5}{|l|}{ Effects of suicidality } \\
\hline Effects on bereaved & 86 & 17.3 & 0.07 & 0.14 \\
\hline Effects on public life & 66 & 13.3 & -0.08 & 0.08 \\
\hline $\begin{array}{l}\text { Immediate death without } \\
\text { suffering reported }\end{array}$ & 26 & 5.2 & -0.28 & 0.13 \\
\hline \multicolumn{5}{|l|}{ Style and wording } \\
\hline Photograph & 64 & 12.9 & -0.003 & 0.94 \\
\hline Several independent & & & & \\
\hline suicidal acts reported & 94 & 18.9 & 0.11 & 0.02 \\
\hline $\begin{array}{l}\text { Reference to a suicide } \\
\text { 'epidemic' }\end{array}$ & 16 & 32 & 0.10 & 002 \\
\hline \multicolumn{5}{|l|}{ Headline explicitly on } \\
\hline suicide & 165 & 33.1 & -0.05 & 0.28 \\
\hline Public myths reported & 11 & 2.2 & 0.13 & 0.005 \\
\hline Article length ${ }^{b}$ & & & 0.06 & 0.20 \\
\hline Sentence length ${ }^{\mathrm{b}}$ & & & -0.02 & 0.71 \\
\hline Emotionality ${ }^{\mathrm{b}}$ & & & 0.05 & 0.31 \\
\hline Dichotomous thinking ${ }^{b}$ & & & 0.13 & 0.004 \\
\hline \multicolumn{5}{|l|}{ Standardised } \\
\hline type/token ratio ${ }^{b}$ & & & 0.05 & 0.29 \\
\hline $\begin{array}{l}\text { a. Point-biserial correlation was use } \\
\text { for continuous variables. All tests ty } \\
\text { b. Continuous variable. All others: } \\
\text { versus absence }(0) \text { of the item char }\end{array}$ & $\begin{array}{l}\text { for dicl } \\
\text {-tailed. } \\
\text { egorica } \\
\text { teristic }\end{array}$ & ous var & $\begin{array}{l}\text { s; Pears } \\
\text { y-coded }\end{array}$ & $\begin{array}{l}\text { relation } \\
\text { nce (1) }\end{array}$ \\
\hline
\end{tabular}

\begin{tabular}{|c|c|c|c|c|}
\hline Codes and subcodes $^{a}$ & $n$ & $\%$ & $r^{b}$ & $P$ \\
\hline \multicolumn{5}{|l|}{ Background information } \\
\hline Focus on suicidal ideation ${ }^{c}$ & 26 & 5.2 & -0.15 & 0.001 \\
\hline Focus on prevention programme ${ }^{c}$ & 31 & 6.2 & 0.09 & 0.06 \\
\hline Focus on suicide research ${ }^{c}$ & 26 & 5.2 & 0.12 & 0.01 \\
\hline Expert opinion reported & 42 & 8.4 & 0.13 & 0.005 \\
\hline Mental disorder related to suicide & 95 & 19.1 & -0.01 & 0.84 \\
\hline Myths debunked & 33 & 6.6 & 0.03 & 0.47 \\
\hline Contact support service & 28 & 5.6 & 0.10 & 0.04 \\
\hline $\begin{array}{l}\text { Suicide-related statistical } \\
\text { data reported } \\
\text { Suffering of suicidal person }\end{array}$ & 51 & 10.2 & 0.08 & 0.08 \\
\hline resulting from suicidal act & 7 & 1.4 & 0.06 & 0.22 \\
\hline \multicolumn{5}{|c|}{$\begin{array}{l}\text { a. Categorical variables, dummy-coded: presence (1) versus absence (0) of the item } \\
\text { characteristic. } \\
\text { b. Point-biserial correlation was used. All tests two-tailed. } \\
\text { c. This variable is identical to the 'main focus' variable under 'basic item } \\
\text { characteristics' (Table 1). }\end{array}$} \\
\hline
\end{tabular}

decrease in suicide rates. On the contrary, a main focus on suicide research, items containing contact information for a public support service and also the reporting of expert opinions were all positively associated with suicide rates (Table 3 ).

The distribution of post-report changes in suicide rates for different sets of media items is displayed in Fig. 2.

\section{Multivariate analysis}

In the multivariate model, repetitive reporting, reports about suicides by jumping, and reporting on public myths about suicide predicted post-item increases in suicide rates. Media items with a main focus on suicidal ideation predicted decreases in suicide rates. The model was significant $(F=2.82$, d.f. $=34,455$, $P<0.001$; Table 4). Model fit in terms of $R^{2}$ was 0.17 , indicating that $17 \%$ of the variance in changes in suicide rates were explained by the model, which is acceptable. ${ }^{29}$ The corresponding effect size

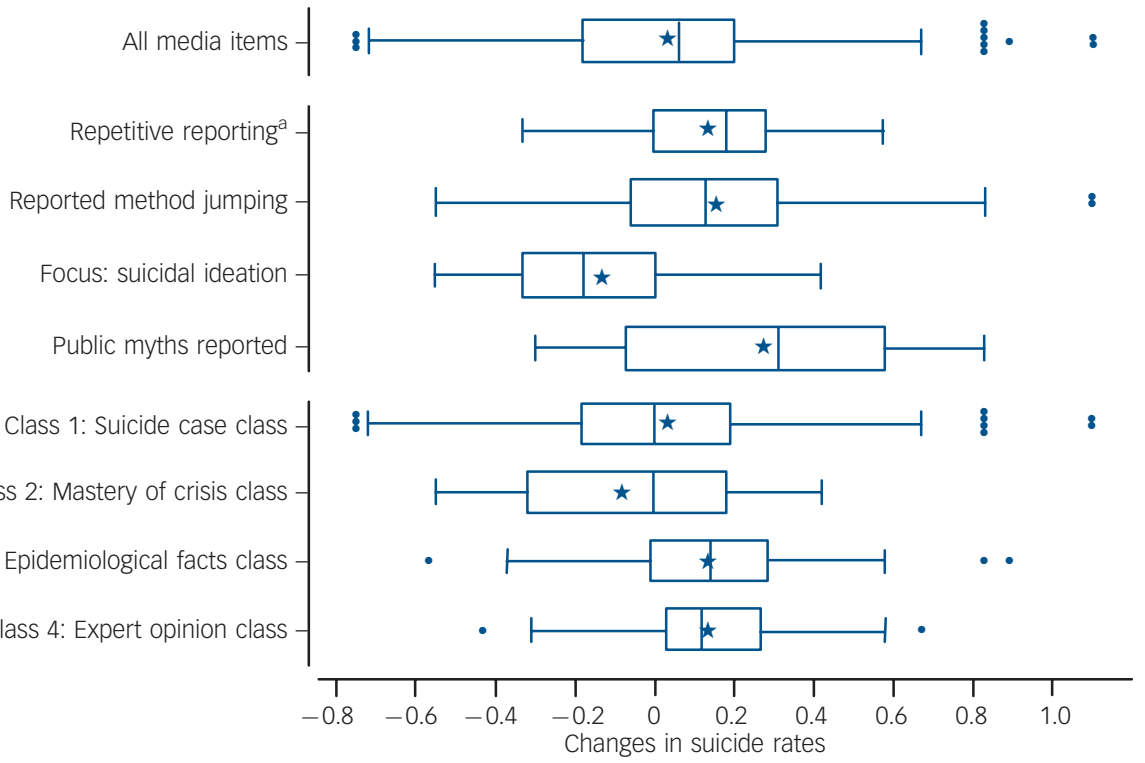

\section{Fig. 2 Changes in suicide rates after the publication of media items.}

Box plots of the difference in suicide rates in the post-publication period (day 0 to 6 after the publication of media items) compared with the pre-publication period (day -14 to -8 ) for different sets of media items. Boxes represent values between 25 th and 75 th percentiles; whiskers, the upper and lower adjacent values; vertical lines, the median; $\star$, the arithmetic mean; $\bullet$, outliers.

a. $>10$ media items. 


\begin{tabular}{|c|c|c|c|c|}
\hline Code and subcode & $b^{\mathrm{b}}$ & $95 \% \mathrm{Cl}$ & $P$ & Part correlation \\
\hline \multicolumn{5}{|l|}{ Quantity of reporting } \\
\hline Repetitive reporting ${ }^{c}$ & 0.01 & 0.003 to 0.02 & 0.005 & 0.10 \\
\hline Density of reporting ${ }^{\mathrm{C}}$ & 0.002 & -0.003 to 0.01 & 0.44 & 0.04 \\
\hline \multicolumn{5}{|l|}{ Main focus } \\
\hline Completed suicide & -0.02 & -0.10 to 0.07 & 0.70 & -0.02 \\
\hline Attempted suicide & -0.01 & -0.11 to 0.10 & 0.93 & 0.001 \\
\hline Homicide suicide & -0.01 & -0.11 to 0.08 & 0.78 & -0.02 \\
\hline Suicidal ideation & -0.15 & -0.27 to -0.03 & 0.02 & -0.11 \\
\hline Prevention programme & 0.01 & -0.14 to 0.15 & 0.98 & 0.01 \\
\hline Suicide research & 0.12 & -0.01 to 0.25 & 0.07 & 0.07 \\
\hline \multicolumn{5}{|l|}{ Reported method } \\
\hline Hanging & -0.09 & -0.18 to 0.004 & 0.06 & -0.07 \\
\hline Jumping & 0.13 & 0.04 to 0.21 & 0.004 & 0.13 \\
\hline Shooting & -0.03 & -0.11 to 0.05 & 0.49 & -0.02 \\
\hline Drowning & 0.07 & -0.06 to 0.20 & 0.28 & 0.06 \\
\hline Poisoning & 0.06 & -0.04 to 0.16 & 0.22 & 0.05 \\
\hline Other method & 0.07 & -0.03 to 0.17 & 0.15 & 0.06 \\
\hline \multicolumn{5}{|l|}{ Prominence } \\
\hline Title page & 0.04 & -0.10 to 0.18 & 0.56 & 0.03 \\
\hline \multicolumn{5}{|l|}{ Fictionality } \\
\hline Content is fictional & 0.09 & -0.03 to 0.21 & 0.15 & 0.07 \\
\hline \multicolumn{5}{|l|}{ Causes of suicidality } \\
\hline Societal problems reported to have increased & 0.03 & -0.11 to 0.17 & 0.67 & 0.02 \\
\hline \multicolumn{5}{|l|}{ Style and wording } \\
\hline Public myths reported & 0.20 & 0.03 to 0.37 & 0.02 & 0.10 \\
\hline Reference to a suicide 'epidemic' & 0.08 & -0.07 to 0.24 & 0.28 & 0.05 \\
\hline Several independent suicidal acts reported & 0.02 & -0.05 to 0.09 & 0.54 & 0.02 \\
\hline Dichotomous thinking & 0.07 & -0.01 to 0.16 & 0.08 & 0.08 \\
\hline \multicolumn{5}{|l|}{ Background information } \\
\hline Expert opinion reported & 0.03 & -0.08 to 0.14 & 0.63 & 0.02 \\
\hline Contact support service & 0.14 & -0.003 to 0.28 & 0.06 & 0.08 \\
\hline
\end{tabular}

$f^{2}$ of 0.21 was medium sized according to the benchmarks proposed by Cohen. ${ }^{30}$ Part correlation coefficients, which represent the unique contributions of individual variables to the variance explained, are provided in Table 4.

Analysis of residuals did not indicate any violations of the assumptions of linear regression, such as non-linearity, nonnormality of error terms, or heteroscedasticity. Autocorrelation plots (ACF, pACF) and Durbin-Watson tests $(D W=1.89)$ did not suggest autocorrelation, and variance inflation factors did not indicate any multicollinearity problems (largest variance inflation factors: 3.05).

\section{t-test}

Post-item changes in suicide rates were larger in regions with high circulation rates of the media items (mean 0.22, s.d. $=0.18)$ than in regions with low circulation rates (mean 0.09, s.d. $=0.09$; $t(710.48)=14.18, P<0.001)$.

\section{Latent class analysis}

The LCA identified a (two-factor) four-class model as the best fit. The model-fit indices of several models tested are reported in Table 5. Of the 14 indicator variables used initially 12 were

\begin{tabular}{|c|c|c|c|c|c|}
\hline Model & $L^{2}$ & Bootstrap $P$ & $\mathrm{BIC}, L^{2}$ & d.f. & Classification error, \% \\
\hline 1-cluster & 3693 & 0.26 & 818.22 & 463 & 0.00 \\
\hline 2-cluster & 3156 & 0.35 & 380.27 & 447 & 0.02 \\
\hline 3-cluster & 3016 & 0.41 & 340.17 & 431 & 0.09 \\
\hline 4-cluster & 2969 & 0.35 & 392.83 & 415 & 0.11 \\
\hline 5-cluster & 2824 & 0.31 & 346.75 & 399 & 0.13 \\
\hline 6-cluster & 2792 & 0.20 & 414.57 & 383 & 0.05 \\
\hline 1-factor & 3156 & 0.34 & 380.27 & 447 & 0.02 \\
\hline 2-factor & 2955 & 0.34 & 279.14 & 431 & 0.02 \\
\hline 3-factor & 2834 & 0.33 & 257.52 & 415 & 0.08 \\
\hline 2-factor ${ }^{a}$ & 2876 & 0.29 & 243.51 & 424 & 0.02 \\
\hline
\end{tabular}


included in the final model. The variables 'pathology reported', which showed only weak discrimination, and 'suffering due to suicidal act', which had a very low level of endorsement across classes, were omitted. The correlation between the two factors was $r=0.30$. Table 6 and Fig. 3 display the endorsement probabilities for each class.

Class 1 (72.2\% of media items), which we conceptualised as the suicide case class, had low probabilities of reporting potentially protective or harmful item characteristics. Media items in this class tended to report on a case of completed suicide. As compared with the other classes, items were more likely reported repeatedly and in short articles (Table 6, Fig. 3).
Class 2 ( $8.8 \%$ of media items), which we conceptualised as the mastery of crisis class, tended to report individual suicidal ideation not accompanied by suicidal behaviour. Repetitive reporting and long articles were rather uncommon in this class. Compared with the other classes, members of this class had the smallest mean number of harmful item characteristics (Table 6, Fig. 3). This was the only class with a negative mean change in the suicide rate after publication (Table 7).

Class 3 ( $7.6 \%$ of media items), which we conceptualised as the epidemiological facts class, comprised media items that tended to report on suicide research and suicide statistics. The reporting of several independent suicidal acts and suicide myths, references to

\begin{tabular}{|c|c|c|c|c|c|c|}
\hline & \multirow[b]{2}{*}{$\begin{array}{c}\text { Frequency } \\
\text { (\%) }\end{array}$} & \multirow[b]{2}{*}{ Mean } & \multicolumn{4}{|c|}{ Joint probability (s.e.) ${ }^{a}$} \\
\hline & & & $\begin{array}{l}\text { Class } 1 \text { : suicide } \\
\text { case class }\end{array}$ & $\begin{array}{l}\text { Class 2: mastery } \\
\text { of crisis class }\end{array}$ & $\begin{array}{l}\text { Class 3: epidemio- } \\
\text { logical facts class }\end{array}$ & $\begin{array}{l}\text { Class 4: expert } \\
\text { opinion class }\end{array}$ \\
\hline $\begin{array}{l}\text { Class assignment probabilities } \\
\text { Protective indicators }\end{array}$ & & & $0.72(0.03)$ & $0.09(0.02)$ & $0.12(0.02)$ & $0.08(0.01)$ \\
\hline $\begin{array}{l}\text { Protective indicators } \\
\text { Focus: suicidal ideation }\end{array}$ & $26(5.2)$ & & $<0.001(<0.001)$ & $0.60(0.13)$ & $0(0)$ & $<0.001(0.01)$ \\
\hline Focus: prevention programme & $31(6.2)$ & & $<0.001(<0.001)$ & $0.07(0.04)$ & $0.002(0.01)$ & $0.75(0.08)$ \\
\hline Focus: suicide research & $26(5.2)$ & & $<0.001(<0.001)$ & $0(<0.001)$ & $0.36(0.07)$ & $0.14(0.06)$ \\
\hline Expert opinion reported & $42(8.4)$ & & $0.006(0.004)$ & $0.06(0.03)$ & $0.18(0.05)$ & $0.71(0.08)$ \\
\hline Myths debunked & $33(6.6)$ & & $<0.001(<0.001)$ & $0.06(0.04)$ & $0.03(0.02)$ & $0.75(0.08)$ \\
\hline Contact support service & $28(5.6)$ & & $<0.001(<0.001)$ & $0.07(0.04)$ & $<0.001(0.002)$ & $0.63(0.09)$ \\
\hline Suicide-related statistical data reported & $51(10.2)$ & & $<0.001(0.002)$ & $<0.001(<0.001)$ & $0.63(0.08)$ & $0.38(0.08)$ \\
\hline \multicolumn{7}{|l|}{ Harmful indicators } \\
\hline Several independent suicidal acts reported & $94(18.9)$ & & $0.12(0.02)$ & $0.07(0.04)$ & $0.72(0.07)$ & $0.11(0.05)$ \\
\hline Reference to a suicide 'epidemic' & $16(3.2)$ & & $<0.001(<0.001)$ & $<0.001(0.001)$ & $0.24(0.06)$ & $0.05(0.04)$ \\
\hline Societal problems reported to have increased & $23(4.6)$ & & $<0.001(<0.001)$ & $<0.001(<0.001)$ & $0.19(0.06)$ & $0.32(0.08)$ \\
\hline Public myths reported & $11(2.2)$ & & $0.01(0.01)$ & $<0.001(<0.001)$ & $0.13(0.05)$ & $<0.001(0.002)$ \\
\hline Dichotomous thinking & & 0.16 & $0.13(0.01)$ & $0.17(0.04)$ & $0.25(0.05)$ & $0.28(0.05)$ \\
\hline \multicolumn{7}{|l|}{ Covariates } \\
\hline Focus: completed suicide & $234(47.0)$ & & 0.57 & 0.03 & 0.43 & 0.11 \\
\hline Repetitive reporting & & 4.44 & 4.97 & 2.31 & 4.21 & 2.15 \\
\hline Article length & & 160.7 & 135.8 & 126.4 & 249.6 & 301.5 \\
\hline
\end{tabular}

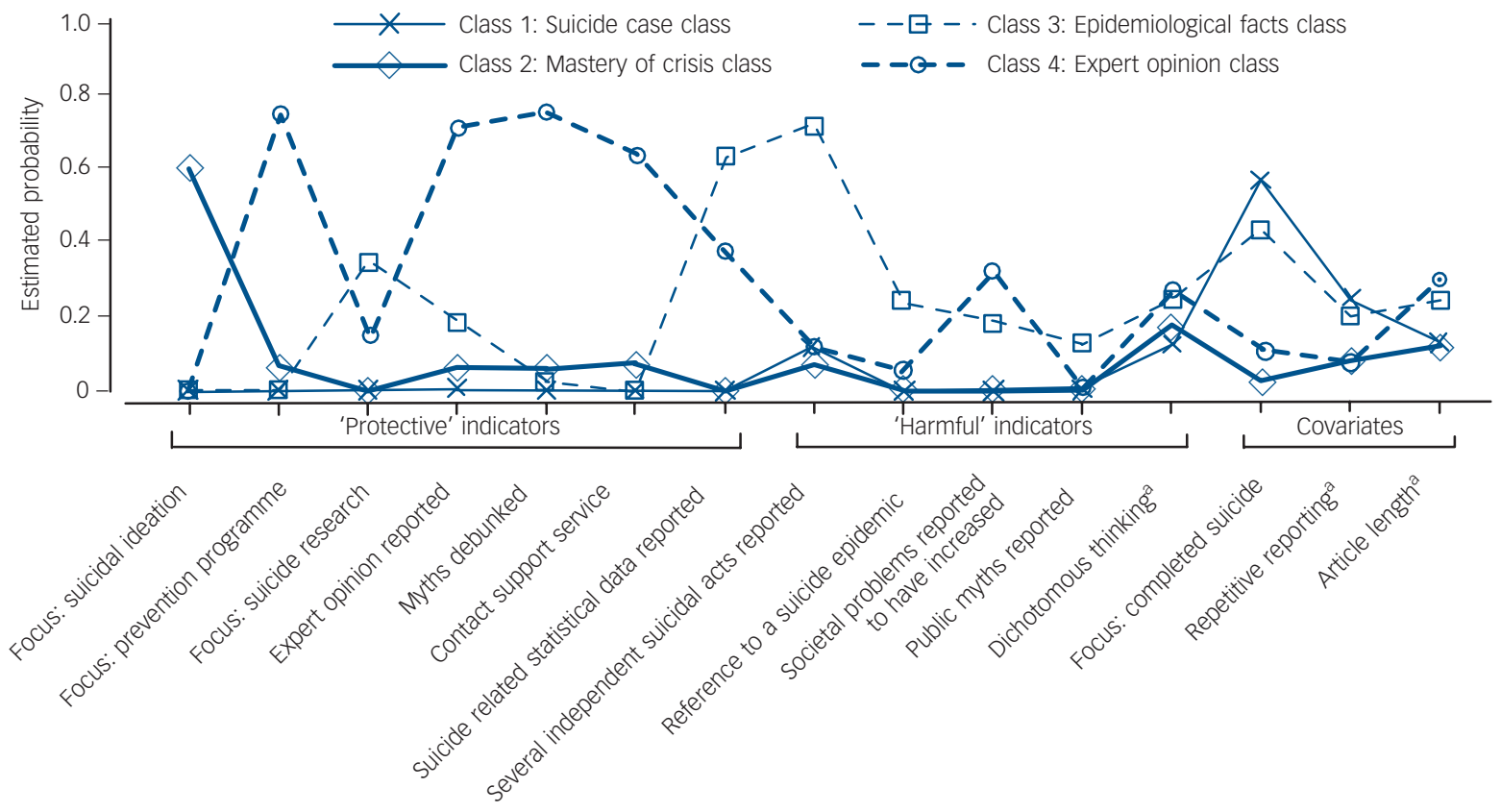

Fig. 3 Latent class analysis: response probabilities.

Estimated probabilities of showing potentially protective and harmful item characteristics for each of the four latent classes of media items.

a. Continuous variable: the value is the class-specific arithmetic mean mapped onto the interval 0 to 1 , where 0 is identified with the lowest and 1 with the highest observed value across classes. 


\begin{tabular}{|c|c|c|c|c|c|}
\hline & \multirow[b]{2}{*}{ All media items } & \multicolumn{4}{|c|}{ Mean (s.e.) } \\
\hline & & $\begin{array}{l}\text { Class } 1 \text { : suicide } \\
\text { case class }\end{array}$ & $\begin{array}{l}\text { Class 2: mastery } \\
\text { of crisis class }\end{array}$ & $\begin{array}{c}\text { Class 3: epidemiological } \\
\text { facts class }\end{array}$ & $\begin{array}{l}\text { Class 4: expert } \\
\text { opinion class }\end{array}$ \\
\hline Protective item characteristics & $0.68(1.20)$ & $0.18(0.42)$ & $1.44(0.62)$ & $1.58(0.94)$ & $3.94(1.26)$ \\
\hline Harmful item characteristics ${ }^{a}$ & $0.29(0.59)$ & $0.13(0.34)$ & $0.09(0.30)$ & $1.40(0.77)$ & $0.50(0.70)$ \\
\hline Total $^{b}$ & $3.42(2.11)$ & $2.85(1.80)$ & $3.75(1.48)$ & $5.40(1.96)$ & $6.19(1.89)$ \\
\hline Suicide rates ${ }^{c}$ & $0.04(0.28)$ & $0.03(0.28)$ & $-0.08(0.27)$ & $0.14(0.29)$ & $0.13(0.23)$ \\
\hline
\end{tabular}

a suicide epidemic, repetitive reporting and long articles were rather common in this class (Table 6, Fig. 3). On average, these articles had the highest number of harmful item characteristics (Table 7).

Class 4 (11.5\% of media items), which we conceptualised as the expert opinion class, was likely to report on suicide prevention programmes and expert opinions, to give contact information on public support services, and to debunk public suicide myths. Articles in this class tended to include the statement that societal problems are increasing, and were characterised by a higher degree of dichotomous thinking. Repetitive reporting was uncommon, and articles were longer than for the other classes (Table 6, Fig. 3). On average, articles in this class had the highest number of potentially protective item characteristics (Table 7, Fig. 3).

Mean posterior assignment probabilities were well over $90 \%$ for all classes (Class 1: 94.8\%; Class 2: 95.7\%; Class 3: 97.7\%; Class 4: $95.5 \%)$, indicating high classification certainty. ${ }^{31}$

\section{Correlations of latent classes with suicide rates}

Assignment to the mastery of crisis class correlated negatively with suicide rates $(r=-0.111, n=490, P=0.014)$. Assignments to the epidemiological facts class $(r=0.124, n=490, P=0.006)$ and the expert opinion class were positively correlated with suicide rates ( $r=0.095, n=490, P=0.035)$. Assignment to the suicide case class was not significantly associated with suicide rates $(r=-0.084$, $n=490, P=0.062$ ).

\section{Discussion}

\section{Key findings}

The possibility of a suicide-protective effect of media items on positive coping in adverse circumstances, which has been discussed in the literature on a purely theoretical basis, was empirically supported by the present findings. Reporting of individual suicidal ideation (not accompanied by attempted or completed suicide) was associated with a decrease in suicide rates. The LCA suggested that media items on suicidal ideation formed a distinctive class of articles, which had a low probability of containing potentially harmful item characteristics. By contrast, media items reporting public suicide myths and repetitive suicide-related reporting were associated with increases in suicide rates. Items with a high probability of containing expert opinions or epidemiological facts were identified as distinctive latent classes of media reports, which tended to be intertwined with unfavourable, sensationalist contents. These classes were associated with increases in suicide rates.

\section{Meaning of the key findings}

The study suggests that prevention of suicidal behaviour by media reports is possible. It expands the research base on the possible impact of suicide-related media content on suicide rates to also include a preventive effect, which we conceptualised as a Papageno effect. In particular, items with a focus on suicidal ideation not accompanied by a suicide attempt or completed suicide may have a protective impact. The reporting strategy underlying these media items seems to deviate from the general tendency to present potentially protective suicide-related information together with potentially harmful item characteristics. Evidence to date suggests the preventive potential of quantitative reductions in sensationalist reporting. ${ }^{10,32}$ To this, the present findings add that the actual reporting of suicidal ideation itself may contribute to preventing suicide. Media items that focus on individual suicidal ideation may enhance identification with the reported individual and thus highlight the reported outcome as 'going on living'. Healthpromoting activities may be most effective when they encourage the publication of articles on individuals who refrained from adopting suicidal plans, and instead adopted positive coping mechanisms in adverse circumstances.

The framing of media items reporting on epidemiology and expert opinions with potentially harmful item characteristics, such as a reference to a suicide epidemic or a statement that suiciderelated societal problems are becoming more pressing, cast some doubt on the role of these types of information in media discourse. Consistent with findings in the field of mass communication, ${ }^{33}$ expert opinions seem to be used as a means of giving an air of seriousness to reporting, but at the same time tend to be embedded in an unfavourable, sensationalist context. Similar conclusions were reached in an analysis of suicide-related print media reports in Australia concerning statistical media items, with the researchers noting that, in their opinion, statistical items were written in a more unfavourable, sensationalist style than media items on completed suicides. ${ }^{34}$ More generally, the tendency to present news in a negative way in the tabloid media has been assumed to result in a negative world image among recipients (the so-called 'scary world hypothesis'). ${ }^{35}$ The effects of such 'mixed messages' on individuals with suicidal constriction clearly warrants further scrutiny. The correlations of items in the expert opinion class and in the epidemiological facts class with increases in suicide rates suggest that these items may have a harmful effect.

\section{Other research}

Dose-response relationships between the quantity of reporting on completed suicide and subsequent suicides, as suggested in the present study, have been repeatedly identified in the literature. ${ }^{1,4}$ Also, this study replicates the finding that changes in suicide rates following the publication of media items are more pronounced in regions where a higher proportion of the population is exposed rather than in regions with a lower exposure. ${ }^{11} \mathrm{~A}$ further finding in line with the literature is the association of reports on one 
particular suicide method (i.e. jumping) with post-item increases in suicide. ${ }^{10}$ Of note, suicides by jumping are more likely to be reported by the print media than suicides by any other method. ${ }^{36}$ Even after controlling for a range of variables likely to influence the probability of reporting (e.g. sociodemographic characteristics of the suicide victim), jumping as a suicide method was found to predict subsequent suicide reporting in the Austrian print media. $^{36}$

\section{Study strengths and limitations}

A strength of the present study is its coverage of all print media items over a period of 6 months that included the word 'suicide', which is likely to have succeeded in the identification of a large proportion of all suicide reports. Furthermore, the coding system applied showed high intercoder reliability, thereby demonstrating high intersubjective analytic consensus. Qualitative approaches are still sparse in suicide research, but are deemed fruitful, and even vital, for research progress, because of their potential to generate new hypotheses. ${ }^{37}$ Mixed-method (i.e. quantitative-qualitative) approaches, as implemented here, are increasingly undertaken in the social sciences and complement each other. ${ }^{38}$ Further strengths of the present study are the comparatively large number of media items analysed qualitatively, the assessment of repetitive reporting on the same story and the adoption of an ecological study design to fit variations in the circulation rate of the analysed media items across the country.

Limitations of the study concern its ecological design, which is appropriate for identifying associations, but not for establishing causality. Methodological approaches using individual-level data are necessary to deal with problems such as the ecological fallacy (i.e. cross-level bias), and further potential confounders beyond seasonality (which was accounted for in the multivariate analysis) Furthermore, the unique contributions of single variables to the variance explained in the multivariate analysis are, albeit nominally significant, small. This may be partly attributable to the definition of the outcome variable as the difference between post-item and pre-item suicide rates. ${ }^{29}$ However, completed suicide is a rare event per se, and thus even small reductions in suicide prevalence seem to be relevant to collaborations with the mass media. Finally, the present study is confined to an analysis of print media. This appears justified by the high exposure of the population to the set of newspapers analysed. In 2005, $71.9 \%$ of the population were regularly exposed to one or several of these newspapers. ${ }^{24} \mathrm{~A}$ recent meta-analysis found that studies of print media effects are more likely to find evidence of a postreport increase in suicide than studies of other media types, ${ }^{3}$ but did not take into account the internet. Future research should also focus on this rapidly emerging medium. ${ }^{39}$

\section{Suggestions for future research}

This study is the first, to our knowledge, to use extensive measures of media item quality. It enabled us to generate more fine-grained hypotheses regarding the effects of suicide-related reporting. Research in other countries is needed to assess the generalisability of the findings. The hypotheses raised should be further examined in qualitative settings, such as through analyses of interviews and focus groups with suicide attempters. Furthermore, increases in suicide rates after the publication of media items have been shown to peak within 1 week of publication. ${ }^{2}$ Future research should also investigate potential patterns of decay in protective media effects, that is, the time pattern of any suicide-protective effect of media reporting.
The present findings add a new perspective to internationally ongoing collaborations between suicide researchers and media professionals. The traditional print and television media, owing to their general lack of space or time, sometimes hesitate to report stories on individuals who adopted coping strategies other than suicidal behaviour in adverse circumstances. The possible role of media reports in preventing suicide may make it worthwhile for journalists of both traditional and online news platforms to follow media guidelines on the reporting of suicide.

Thomas Niederkrotenthaler, MD, PhD, MMSC, Department of General Practice and Family Medicine and Department of Medical Psychology, Center for Public Health, Medical University of Vienna, Vienna, Austria; Martin Voracek, DSc, DMSc, PhD, Department of Basic Psychological Research, School of Psychology, University of Vienna, Vienna, Austria; Arno Herberth, MPhil, Department of German Language and Literature, University of Vienna, Vienna, Austria; Benedikt Till, DSc, Department of Communication, University of Vienna, Vienna, Austria; Markus Strauss, Department of Medical Psychology, Center for Public Health, Medical University of Vienna, Vienna, Austria; Elmar Etzersdorfer, MD, Furtbach Hospital, Stuttgart, Germany; Brigitte Eisenwort, PhD, Gernot Sonneck, MD, Department of Medical Psychology, Center for Public Health, Medical University of Vienna, and Ludwig Boltzmann Institute for Social Psychiatry, Vienna, Austria

Correspondence: Dr Thomas Niederkrotenthaler, Department of Medical Psychology, Center for Public Health, Medical University of Vienna, Severingasse 9, A-1090 Vienna, Austria. E-mail: thomas.niederkrotenthaler@meduniwien.ac.at First received 23 Dec 2009, final revision 20 May 2010, accepted 25 May 2010

\section{Funding}

We thank the Austrian Academy of Sciences for funding the project through a DOC-team scholarship (grant number 70034 to B.T.; 70035 to A.H.; 70036 to T.N.).

\section{Acknowledgements}

We thank Jon Kimber for his assistance with the preparation of the manuscript.

\section{References}

1 Phillips DP. The influence of suggestion on suicide: substantive and theoretical implications of the Werther effect. Am Sociol Rev 1974; 39 $340-54$

2 Stack S. Social correlates of suicide by age. Media impacts. In Life Span Perspectives of Suicide. Time Lines in the Suicidal Process (ed A Leenars): 187-213. Plenum Publishing, 1992.

3 Stack S. Suicide in the media: a quantitative review of studies based on nonfictional stories. Suicide Life Threat Behav 2005; 35: 121-33.

4 Pirkis JE, Burgess PM, Francis C, Blood RW, Jolley DJ. The relationship between media reporting of suicide and actual suicide in Australia. Soc Sci Med 2006; 62: 2874-86.

5 World Health Organization (WHO). Preventing Suicide. A Resource for Media Professionals. WHO, 2008 (http://www.who.int/mental_health/prevention/ suicide/resource_media.pdf).

6 Hawton K, Williams K. Influences of the media on suicide. Researchers, policy makers, and media personnel need to collaborate on guidelines. BMJ 2002; 325: $1374-5$.

7 Pirkis J, Blood W, Beautrais A, Burgess P, Skehan J. Media guidelines on the reporting of suicide. Crisis 2006; 27: 82-7.

8 Schikaneder E. The Magic Flute: Libretto. Metropolitan Opera Guild, 1990

9 Ringel E. Selbstmord in der Oper [Suicide in the Opera]. Lecture at the conference of the International Association of Suicide Prevention in Vienna, 1985 [in German: video cassette]. Video Sattler, 1985.

10 Sonneck G, Etzersdorfer E, Nagel-Kuess S. Imitative suicide on the Viennese subway. Soc Sci Med 1994; 38: 453-7.

11 Etzersdorfer E, Voracek M, Sonneck G. A dose-response relationship of imitational suicides with newspaper distribution. Aust N Z J Psychiatry 2001; 35: 251.

12 Chan KPM, Yip PSF, Au J, Lee DTS. Charcoal-burning suicide in post-transition Hong Kong. Br J Psychiatry 2005; 186: 67-73.

13 Hassan R. Effects of newspaper stories on the incidence of suicide in Australia: a research note. Aust N Z J Psychiatry 1995; 29: 480-3. 
14 Pirkis J, Blood RW. Suicide and the media: Part II. Portrayal in fictional media Crisis 2001; 22: 155-62.

15 Barber ME, Marzuk PM, Leon AC, Portera L. Aborted suicide attempts: a new classification of suicidal behaviour. Am J Psychiatry 1998; 155: 385-9.

16 McQuail D. Mass Communication Theory. Sage, 2008.

17 Hohn H. A Linguistic Analysis of BBC Radio News. Grin, 2007.

18 Sotirovic M. Effects of media use on complexity and extremity of attitudes toward the death penalty and prisoners' rehabilitation. Media Psychol 2001; 3: $1-24$.

19 Eldridge J. Media Group Reader: News Content, Language, and Visuals. Routledge, 1995.

20 Ertel S. Erkenntnis und Dogmatismus [Perception and dogmatism]. Psychologische Rundschau 1972; 23: 241-69.

21 Mende M. Sensationalismus als Produktgestaltungsmittel [Sensationalism as a Means of Presenting a Product]. Botermann \& Bottermann, 1996.

22 Krippendorff K. Content Analysis: An introduction to its Methodology. Sage, 2004.

23 Statistics Austria. Statistical Data: Population \& Regional Statistics [partially in German]. Statistics Austria, 2010 (http://www.statistik.gv.at/web_en/).

24 Media Analyse Austria. Media-Analyse-Studien [Media analysis]. Verein Arbeitsgemeinschaft Media-Analyse, 2006 (http://www.media-analyse.at/ studies.do).

25 Breslau N, Reboussin BA, Anthony JC, Storr CL. The structure of posttraumatic stress disorder: latent class analysis in 2 community samples. Arch Gen Psychiatry 2005; 62: 1343-51.

26 Garson GD. Statnotes: Topics in Multivariate Analysis: Latent Class Analysis. GD Garson, 2009 (http://faculty.chass.ncsu.edu/garson/PA765/latclass.htm).

27 Magidson J, Vermunt JK. Latent class factor and cluster models, bi-plots and related graphical displays. Sociol Methodol 2001; 31: 223-64.
28 Fabrigar LR, Wegener DT, MacCallum RC, Strahan EJ. Evaluating the use of exploratory factor analysis in psychological research. Psychol Methods 1999; 4: 272-99.

29 Nau RF. What's a good value of R-squared? Duke University, 2009 (http:// www.duke.edu/ rnau/rsquared.htm).

30 Cohen J. Statistical Power Analysis for the Behavioural Sciences. Erlbaum 1988.

31 Nagin DS. Group-Based Modeling of Development. Harvard University Press, 2005.

32 Niederkrotenthaler T, Sonneck G. Assessing the impact of media guidelines for reporting on suicides in Austria: interrupted time-series analysis. Aust NZ J Psychiatry 2007; 41: 419-28.

33 Krüger C. Journalistische Berichterstattung im Trend der Zeit: Stilstrategie und Textdesign des Nachrichtenmagazins FOCUS [Journalism in the trend of time: stylistic strategies and text design in the print media FOCUS. Dissertation, in German]. University of Münster, 1995.

34 Pirkis J, Francis C, Blood RW, Burgess B, Morley B, Stewart A, Putnis P. Reporting of suicide in the Australian media. Aust N Z J Psychiatry 2002; 36 190-7.

35 Heitmayer W, Hagan J. International Handbook of Violence Research. Kluwer Academic Publishers, 2003

36 Niederkrotenthaler T, Till B, Herberth A, Voracek M, Kapusta ND, Etzersdorfer $E$, et al. The gap between suicide characteristics in the print media and in the population. Eur J Public Health 2009; 19: 361-4.

37 Hjemeland $\mathrm{H}$, Knizer BL. Why we need qualitative research in suicidology. Suicide Life Threat Behav 2010; 40: 74-80.

38 Creswell JW, Clark VLP. Designing and Conducting Mixed Methods Research. Sage, 2007.

39 Curah A. What's Happening to our News? An Investigation of the Likely Impact of the Digital Revolution on the Economics of News Publishing in the UK. Reuters Institute for the Study of Journalism, 2009 (http:// reutersinstitute.politics.ox.ac.uk/publications/risj.html). 